\title{
La sujeción de la mujer: feminidad ideal
}

\section{Pilar Errázuriz ${ }^{1}$}

Con objeto del Aniversario: 150 años de Sobre la Libertad y 140 años de El sometimiento de las mujeres de J. S.Mill. Ponencia en la Universidad de Chile, Escuela de Derecho, 14-15-16 dic.2009.

En el año 1872, Doña Martina Barros Borgoña pionera feminista en nuestro país, a sus 22 años de edad traduce un texto de John Stuart Mill y lo publica en la Revista de Santiago bajo el título de "La Esclavitud de la Mujer". Lo acompaña de un polémico prólogo que produce reacciones positivas en las élites de los varones liberales de la época entre los que se contaban Orrego Luco, Miguel Luis Amunátegui y Vicuña Mackenna y negativas en las contemporáneas de su mismo sexo: incluso las amigas no aprecian su trabajo y según relata Martina en sus memorias la consideraron una "niña peligrosa". Será solo 35 años más tarde cuando las sufragistas, de la mano de Delia Matte, le prestarán atención invitándola a dar una conferencia sobre el voto femenino. Fueron los años que necesitaron las mujeres chilenas progresistas para subirse al carro de las reivindicaciones que no fueran en nombre de las virtudes religiosas.

Siete años más tarde de la publicación de Martina y a 10.000 kilómetros de nuestro pequeño país, un incipiente 'médico del alma' en la Viena decimonónica, Sigmund Freud, con 27 años de edad y necesitado de fondos, se aboca a la traducción al alemán de los textos de Stuart Mill bajo la supervisión del filósofo y filólogo Theodor Gomperz: Platón, Estudios sobre la cuestión obrera y el socialismo, y el texto de La sujeción de la mujer.

Corrían tiempos de misoginia en la Europa romántica: las mujeres que reivindicaban derechos ciudadanos en la naciente Democracia amenazaban a las élites masculinas. Mientras Sigmund traducía a Mill en 1880, Alexandre Dumas hijo, miembro de la Academia Francesa, contaba ya con una segunda edición 
de su libro cuyo título es muy significativo: Las mujeres que matan y las mujeres que votan. Las obras literarias de Dumas que preceden esta cruda conclusión de su pensamiento constituyen la representación por excelencia de la idealización de la figura femenina: solo son amables y amadas las mujeres que se entregan, lánguidas, subordinadas al amor y al varón. En 1848, mientras en Nueva York Lucrecia Mott y Elizabeth Cady Stanton publicaban el primer documento reclamando derechos ciudadanos para las mujeres, Alejandro Dumas hijo publicaba en Francia La Dama de las Camelias.

En esos años, en Inglaterra los prerrafaelistas ingleses pintaban mujeres místicas de inspiración mariana, y mientras Stuart Mill terminaba en Avignon el borrador de La Sujeción de la Mujer en 1861, Dante Gabriel Rossetti se preparaba para pintar su gran obra, la Beata Beatrix que inaugura un bagaje simbólico en la estética que contribuirá a asociar a la mujer con la naturaleza, con la inmanencia, con criaturas etéreas y bellezas entregadas al deseo masculino. Será la ambición de la fantasía de los varones que repudian a las incendiarias de Paris la que promueve una representación de las mujeres que contradice la pretendida autonomía de las féminas rebeldes. A tal punto mujer y pasividad, mujer y alogicidad, mujer e inmanencia fueron conceptos asociados, que el sexólogo Weininger se permitió culminar el siglo XIX afirmando que aquellas que reivindicaban sus derechos eran mujeres más masculinas que femeninas....

¿Y qué decir de nuestro maestro del Psicoanálisis? Sin duda su traducción de Stuart Mill al alemán debió ser excelente y se dice que fue una transcripción elegante y original (Dadoum, 1984, 42). Al contrario de la chilena Martina Barros, Freud no prologó los textos ni se declaró simpatizante de los mismos. Mientras hacía su servicio militar el año 79 y 80, Sigmund usaba su tiempo libre para traducir estos textos libertarios, sino libertinos. Podemos pensar que no fue fácil para el futuro médico esa pequeña aventura de traducción: su servicio militar sin duda desafiaba su masculinidad y la lectura del osado Stuart Mill lo amenazaba con innovaciones en las relaciones de género. El joven Freud no podía sino mostrarse intranquilo. Su intranquilidad aún perdura tres años más tarde, especialmente ahora que ha conocido a la mujer que será su esposa. Así, escribe a su amada un 15 de noviembre del año 83 a propósito de las reflexiones que le 
suscitaran los escritos de Mill: “la situación de la mujer no podrá ser más que lo que es: en los años jóvenes, una amante adorada y en los de madurez, una mujer amada" ${ }^{2}$.

Sucede que un año antes de conocer a Martha Bernays, su futura esposa, Freud se embarca en una azarosa aventura con su colega y amigo Josef Breuer y es aquella de interpretar para el beneficio de sus nuevas teorías las dolencias que sufría una joven feminista, Bertha Pappenheim, quien a sus 21 años y dominando la lengua inglesa, ya estaría al corriente de las ideas progresistas de Mill. Sucede también, que Bertha (Anna O. para la leyenda que ilustra los principios del psicoanálisis) era amiga de Martha la novia de Freud y sucede que la supuesta curación de la que se habría beneficiado por el psicoanálisis en el año 82 se reveló ser producto de un wishful thinking de ambos psicólogos. El propio Freud reconoce en otra carta a Martha en el mismo año 83 que Bertha ha debido de internarse en el sanatorio de Gross-Enzersdorf, contradiciendo la supuesta curación en manos de Breuer. Todavía para 1887, Bertha seguía enferma. Solo se conoce la cura de Pappenheim en 1890 cuando puede iniciar su trabajo social feminista protegiendo a mujeres violentadas en albergues construidos para ese fin y reivindicando la emancipación de las mujeres judías. Las malas lenguas aseguran que Bertha no padeció de histeria sino de una enfermedad física llamada meningitis tuberculosa, que estaba muy extendida en Europa (Eysenk, 1988). De manera que tanto diagnóstico, como proceso psicoanalítico y como curación de Anna O., el mito fundante del psicoanálisis, se han visto cuestionados por los historiógrafos revisionistas. Los desajustes de la joven feminista, reivindicativa e independiente, unidos o no a una causa orgánica son interpretados por los psicoanalistas como síntomas histéricos....

Tenemos entonces una constelación de circunstancias que rodean a nuestro joven Sigismund Schlomo: el servicio militar en una Europa ad portas del antisemitismo; la traducción de textos ingleses amenazantes para la hegemonía masculina; el amor por Martha, amiga de una feminista que resulta ser la protagonista de la azarosa aventura con Breuer que culmina con la construcción de una leyenda... Por su parte, Anna, la paciente feminista, denostó el psicoanálisis tanto más cuando su médico quiso ver en su dedicación social una inspiración angelical en lugar de una labor política. Para Freud, esos años no deben haber sido 
tranquilos. Su visión tradicional y convencional de las relaciones de género se debe haber vapuleado. Son años que coinciden con la traducción de los textos de Mill, con la desventura con la paciente de Breuer, y con el inicio de su propio autoanálisis. Algo tenía que mantenerse firme: la idealización de la mujer.

De modo que el Maestro escribe el año 83 a su futura esposa la siguiente carta: "estamos de acuerdo, creo, tú y yo, de estimar que el quehacer del hogar, la educación de los niños y los cuidados a prodigarle, acaparan completamente a un ser humano y excluyen casi toda posibilidad de ganar dinero. ¿Debería, por ejemplo considerar a mi dulce y delicada querida como una competencia? En ese caso, terminaría por decirlo, como lo he dicho hace diez y siete meses, que la amo y pondré todo de mi parte para sustraerla a esta competencia y que le atribuyo como dominio exclusivo la apacible actividad de mi hogar". Y añade en referencia a los escritos de Mill, "es posible que una educación nueva llegue a ahogar las cualidades delicadas de la mujer, su necesidad de protección que no impide para nada sus victorias, de modo que ella pueda, como los hombres, ganarse la vida. Es posible que, en ese caso, se deplore la desaparición de la cosa más deliciosa que el mundo nos ofrezca: nuestro ideal de la feminidad" (Jones, 1970, 87) ${ }^{3}$.

Mientras nuestro psicoanalista partía su estudio de la subjetividad femenina por la conclusión, en nuestro país Martina Barros hacía una definición bastante acertada acerca de los efectos de la subordinación de las mujeres en nuestra realidad psicológica: es "culpa (de) esta 'educación viciosa' de mirar al hombre 'desde la cuna como un ser superior...'. En cambio, a la mujer, esa misma educación crea un sentimiento de inferioridad que '... echa raíces en su espíritu, se apodera de su corazón y llena su vida entera."'. Martina "critica que la sociedad señale a la mujer el matrimonio como su único destino, lo cual confirma posteriormente en sus Memorias cuando escribe que 'Sin preparación alguna se nos entrega al matrimonio para ser madres... y para eso ni la Iglesia, ni la ley, ni los padres, ni el marido nos exige otra cosa que la voluntad de aceptarlo'. Para Martina, mientras 'la sociedad dice: la mujer ha nacido para el matrimonio; la naturaleza dice: la mujer ha nacido para vivir'." (Stuven, ver ref.)

Transcurrió el tiempo para Sigmund en su búsqueda acerca de los misterios del sujeto. Si bien la mayoría de sus pacientes eran mujeres, su estudio se centró en el sujeto masculino, el uno 
universal, nicho en el que nacemos ambos sexos. La mujercita en su primera infancia es "un hombrecito" asegura su teoría, en términos de una libido o energía sexual idéntica para ambos sexos (masculina), y en el curso de su crecimiento debe renunciar a esta supuesta identidad masculina y devenir femenina. De este modo, el Maestro hacia el final de su vida describe tres destinos para las mujeres: -uno conduce a la inhibición sexual o a la neurosis; otro, a la transformación del carácter en el sentido de un complejo de masculinidad; y el otro, al fin, a la feminidad normal" (Freud, 1981, 3172). Esta última presupone que la niña advierta "en seguida la diferencia [de no tener pene como el pequeño varón] y -preciso es confesarlo- también su significación. Se siente en grave situación de inferioridad" (Freud, 1981, 3172).

Al igual que Martina Barros, el fundador del psicoanálisis llegará a la misma conclusión: la subjetividad de las mujeres se construye sobre la base de una organización simbólica jerárquica en la cual lo masculino y sus insignias están por sobre lo femenino y la carencia de aquellas. Solo que el Maestro no encara la cuestión desde una lectura crítica. Naturaliza la jerarquía desde su interpretación del origen de la cultura: según su texto de Tótem y Tabú el mito fundante consistiría en una horda primitiva cuyo padre, dueño de todas las mujeres es asesinado por sus hijos para instalar un nuevo régimen civilizatorio. Las mujeres tendrían un tiempo de gracia y autonomía, hasta que muy pronto la organización del sistema de parentesco las coloca en un lugar de objeto de intercambio entre los varones gracias al tabú del incesto y a la vigilancia del Tótem que simboliza al padre autoritario.

En este texto podemos intuir una metáfora frente al nuevo régimen que acaba de instalarse en Europa, es decir, la abolición del derecho divino, la muerte del padre, el gobierno en manos de la fratría de los jóvenes demócratas, la colaboración de las mujeres codo a codo con sus hermanos durante la revolución y finalmente su sujeción al espacio doméstico y reproductivo. El estudio del sujeto femenino deviene entonces el estudio de su sujeción. Es un sujeto sujetado en el mejor de los casos. En el peor, es un objeto de intercambio entre los grupos de varones para estabilizar el devenir social.

Mientras la teoría psicoanalítica colabora a reconstruir la masculinidad amenazada de la sociedad, un criterio de realidad debe imponerse para el Maestro: muchas de sus pacientes se 
convertirán en discípulas, luego en psicoanalistas y finalmente en profesionales. Incluida su propia hija Ana ¿Cómo asimilar este fenómeno a la vista de sus ideas tradicionales de la feminidad? Resulta de una gran simpleza: lo femenino sigue siendo lo sujetado. Las mujeres que aspiran a la emancipación y a la igualdad son aquellas que no admiten su diferencia, léase: que no admiten la inferioridad de su sexo que según la teoría solo se puede compensar por una maternidad activa y gozosa. Frente a los reclamos de las colegas mujeres, Freud escapa con una galante pirueta como él mismo reconoce, año 33: "la tesis de la bisexualidad nos hacía facilísimo evitar toda descortesía, pues llegado el caso, salíamos del apuro diciendo a nuestras antagonistas "eso no va con usted: usted es una excepción, pues en este punto concreto es usted más masculina que femenina" (Freud, 1981, 3166-3167). En efecto, ya desde el año 27 un grupo de psicoanalistas mujeres disidentes de la teoría se oponían a sus planteamientos sobre el monismo sexual y tal como lo reconoce el propio Freud "se apresuraban a expresar sus sospechas de que nosotros, sus colegas masculinos, no habíamos superado prejuicios profundamente arraigados contra la feminidad, prejuicios que, por parciales que fueran, invalidaban nuestras investigaciones".

Para el Maestro la revindicación de los derechos de la mujer aparece como producto de un fracaso de la feminidad. En los años 20 Freud dirá al respecto de una joven homosexual que tiene como paciente: "Era una apasionada defensora de los derechos femeninos; encontraba injusto que las muchachas no gozasen de las mismas libertades que los muchachos y se rebelaba en general contra el destino de la mujer" (...) presentaba "indicios de masculinidad [como] algunas de sus cualidades intelectuales, tales como su penetrante inteligencia y la fría claridad de su pensamiento (...)" (Freud, 1981, 2550) ${ }^{4}$. Es más, nuestro psicoanalista entusiasmado por su teoría sobre la bisexualidad llega a afirmar que esta muchacha: "se transformó en hombre y tomó como objeto erótico a la madre en lugar del padre"... No solo se trata de una mujer masculina, sino de una mujer hombre. De modo que concluimos que en el imaginario del maestro una mujer inteligente, que reclama sus derechos de igualdad con el hombre no solo es masculina, sino que se puede transformar en hombre. Precursor del feminismo postmoderno que sostiene que no solo el género es una construcción cultural sino también el sexo... 
Ahora bien, para gran turbación de quienes estudiamos la teoría freudiana, estos propósitos del psicoanalista no difieren mucho de los propósitos misóginos de Otto Weininger, cuando éste asegura que "hoy en día la verdadera mujer no pide la emancipación, más bien solo las mujeres más masculinas lo hacen, las que desconocen su propia naturaleza y no perciben los motivos de sus actos cuando creen que hablan en nombre de las mujeres" y añade "en lo que concierne a las mujeres emancipadas: es solo el hombre en ellas el que quiere emanciparse". Más aún: "el grado de emancipación de las mujeres es idéntico al grado de su virilidad". Con respecto a la homosexualidad femenina, Weininger piensa que "la mujer que está atraída sexualmente por una mujer, es, por supuesto, un medio hombre" (Weininger, 1903). El primer grupo de la segunda opción que plantea Freud consistiría, entonces, en mujeres transformadas en hombres o según lo indica Weininger, en medio hombres.

No solo el psicoanálisis supone una desviación al destino de mujer la reivindicación de igualdad de derechos, sino que el arte y la literatura del último tercio del siglo XIX se ocupa de construir una representación de la mujer fálica, malvada, asesina y amenazante. No bastó la construcción ideal de los años anteriores, las musas, las místicas, los ángeles del hogar, sino que -frente al aumento de las pretensiones de autonomía y poder de las mujeres- era necesario contarle al mundo acerca de su maldad. Del mito mariano, las elites masculinas pasarán al mito de Eva, de Salomé, de la Medusa. Decenas de Salomé decapitando al Bautista pueblan la cultura: en la pintura, el teatro, la literatura. Su figura se extenderá como símbolo de la femme fatal sedienta del triunfo sobre los varones: sobre dos generaciones de varones, Herodes el Tetrarca, viejo, débil y manipulado, y el santo, que -espíritu puro- pierde la cabeza (en forma literal) por ella, mala mujer. No olvidemos que Salomé reivindicaba la sexualidad de su madre frente a la condena moral por su concubinato con Herodes. No olvidemos también que la leyenda del baile de Salomé se utilizó como pretexto para encubrir el hecho que Herodes mandó él mismo a matar a Juan el Bautista por razones políticas (Lida de Malkiel, 1977, 161-166).

Heredera de la Comuna de Paris, la resurrección de Salomé por el pintor simbolista Gustave Moreau que se obsesiona con mostrar la maldad (y por qué no, la belleza) de dos generaciones 
de mujeres que traicionan a los varones, se continúa con la mujer satánica del ilustrador Rops, la mujer vampiro de Munch, la mujer carroña de Zola, Mirbeau, Beaudelaire, Maupassant y de los hermanos Goncourt y culmina en el nuevo siglo con la devoradora de hombres del pintor Mossa, que con el sugestivo nombre de Ella y con cara necia, ojos vacíos de pensamiento y grandes pechos, yace en cuclillas sobre un cerro de hombrecitos muertos y vencidos. La femme fatale que sobrevive al cambio de siglo y que se perpetúa en la Dama de las Camelias en la ópera de Verdi y en la película interpretada por Greta Garbo, y la Salomé de la obra de Byron, se encontrarán en los años 20 con la construcción de una mujer masculina, anunciada por Freud y por Weininger: el personaje de La Garçonne del escritor Victor Margueritte. 300.000 ejemplares se venden en 1922, el año de su publicación y para finales de la década, se han vendido un millón de libros. La garçonne baila, bebe, consume drogas, tiene relaciones bisexuales, lleva pelo corto y ropa deportiva. Asiste a clases en la Sorbonne y tiene un trabajo interesante. Finalmente, se casa con un distinguido burgués. Privilegio de la clase emergente: la mujer emancipada es más masculina que femenina.

Para estas fechas, en Inglaterra se habían cursado 2588 peticiones para el sufragio femenino bajo la influencia de John Stuart Mill consiguiendo el sufragio universal femenino para el año 28. El año 20 la Austria de Freud había aceptado el voto de las mujeres, así como su país de nacimiento, Checoslovaquia. Francia no accedería hasta 1944 al sufragio femenino, al término de la segunda guerra y cinco años antes del célebre libro de Simone de Beauvoir El Segundo Sexo, que, al igual que el prólogo de Martina Barros, levantó enormes polémicas esta vez especialmente en los hombres de letras. Ese mismo año, 1949, Chile se integra a la comunidad más avanzada concediendo el voto para las mujeres como culminación de un movimiento sufragista importante de mujeres en el que se destaca el MEMCH con Elena Caffarena a la cabeza.

Por su parte, Freud luego de más de medio siglo de estudio e investigación sobre los sujetos, murió convencido que los dos sexos tienen algo en común y esto es el repudio de la feminidad. "Los dos temas, que se corresponden, son: en la mujer, la envidia del pene -una aspiración positiva a poseer un órgano genital masculino- [dicho de otro modo: el deseo de ser hombre] y en el 
varón, la lucha contra su actitud pasiva o femenina frente a otro varón (...)" (Freud, 1937, 3363) escribe en su último texto del año 36. Tres años antes, en su conferencia sobre la feminidad el Maestro reflexionaba acerca de la feminidad como un enigma: "sobre el problema de la feminidad han meditado los hombres en todos los tiempos (...). Tampoco vosotros, los que me oís, os habréis excluido de tales cavilaciones. Los hombres, pues las mujeres sois vosotras mismas el enigma" (Freud, 1933, 3164-3165).

De manera que tenemos los siguientes elementos para realizar alguna operación lógica si es que eso es posible: Por una parte, hombres y mujeres repudian la feminidad, ambos sexos valoran lo masculino por sobre lo femenino, las mujeres solo acceden a la feminidad si son sujetos sujetados, las mujeres que reivindican su liberación y emancipación son más masculinas que femeninas.... Por otra parte no olvidemos su declaración de principios después de traducir los textos de Mill: la igualdad con los hombres tendría como consecuencia que se deplore la desaparición de la cosa más deliciosa que el mundo nos ofrezca: nuestro ideal de la feminidad que, a su vez parece ser un enigma. ¿Cómo entenderlo? ¿La cosa más deliciosa del mundo, la feminidad, es lo que repudian hombres y mujeres lo que los reúne en un territorio común? ¿Es este el enigma? Creemos que no hay tal enigma: para el sistema sexo-género en el cual la mitad de la humanidad ha dominado a la otra mitad por espacio de al menos veinte siglos, la feminidad en clave de sujeción e inferioridad ha sido una heterodesignación conveniente y necesaria para mantener la hegemonía. Las mujeres que comprendieron que su destino femenino no corría paralelo con el de la sujeción, se arriesgaron al vituperio, a ser consideradas masculinas, sin embargo reivindicaron sus derechos durante todo un siglo hasta los logros actuales que aún no están completados. El enigma más bien es para los sabios de todos los tiempos, ya que no para nosotras las mujeres. Convivir emancipación, liberación y feminidad es una realidad cotidiana que no se contradice por más que en el análisis de la subjetividad se pretenda lo contrario. Es la construcción de una cierta feminidad que ha construido la sociedad patriarcal y en la cual no nos reconocemos (inmanencia, alogicidad, pasividad) que se disfraza de enigma.

Sigismund Schlomo no logró en tantos años de estudio dilucidar el enigma. ¿O quizás no quiso reconocerlo? En cualquier 
caso en su última conferencia añadió la siguiente recomendación: "es preciso tener en cuenta que la mujer integra también lo generalmente humano" (Freud, 1981, 3178). Este insight de última hora es notable...Darwinista él, ¿habría pensando en algún momento que esto no era así? El Diccionario de Psicoanálisis de Roudinesco y Plon se muestra indulgente frente a la buena fe de esta afirmación. Sostiene que "se parece en cierto modo a aquella, jurídica, de Antoine de Caritat, marqués de Condorcet (17431794), el gran teórico de la emancipación de las mujeres. A más de un siglo de intervalo, se trataba para el filósofo francés como para el sabio vienés de mostrar que el ámbito de lo femenino debía ser pensado en tanto parte integrante del universal humano y, por lo tanto, bajo la categoría de un universalismo, único capaz de dar un fundamento verdadero al igualitarismo. Según esto, Freud se une a los ideales del igualitarismo universalista de Descartes hasta Las Luces" (Roudinesco y Plon, 1998, 996).

Más bien, el enigma sería el siguiente: dilucidar si el sabio no logró reconocer la arbitrariedad de la desigualdad entre los sexos, tan ocupado estaba por su imaginario convencional, o bien sospechar que se negó a admitir la legitimidad de las reivindicaciones que apoyó Stuart Mill al igual que hizo con el caso Anna O. la feminista cuya historia distorsionó con la complicidad de Breuer y más tarde de su discípulo y biógrafo Jones. Quizás Anna Freud quien fue la Antígona de su padre, hubiera podido revelar estas cuestiones. Sin embargo su política de retención de mucho material secreto de su padre no ha hecho más que alimentar los rumores, las presunciones y la desconfianza.

En todo caso, la sujeción como ideal de feminidad (que el propio Freud practicó con su hija Ana) concuerda con las aspiraciones de una generación intelectual vienesa atemorizada por la feminización de la sociedad, por el judaísmo y la sexualidad y por la decadencia del patriarcado (Roudinesco y Plon, 1998, 996). Sin duda, esta generación debió haberse sentido amenazada por las propuestas de Stuart Mill sobre los derechos ciudadanos de las mujeres que, al final, triunfarían por sobre la sinrazón del pensamiento hegemónico. 


\section{Notas}

1 Doctora en Estudios de Género de la Universidad de Valladolid, académica del Centro de Estudios de Género y Cultura en América Latina (CEGECAL) de la Universidad de Chile.

2 Freud, S., 15 noviembre 1883, carta a Martha Bernays.

3 La cursiva es mía.

4 La cursiva es mía para señalar que queda implícito para Freud que la 'defensa de los derechos femeninos' es, paradójicamente, una actividad masculina... de una mujer 'transformada en hombre'. De mucha ayuda hubiera sido el conocimiento de los conceptos de género para la teoría, en orden a separar lo biológico de lo psíquico.

\section{Bibliografía}

Dadoun, Roger. Freud. Barcelona: Ed. Argos Vergara, 1984.

Eysenck, Hans. Decline and fall of the Freudian empire. New York: Viking, 1985.

Freud, Sigmund. Obras completas. Madrid: Biblioteca Nueva, 1981.

Jones, Ernest. Vida y obra de Sigmund Freud. Barcelona: Anagrama, 1970.

Lida de Malkiel, M. Rosa. Herodes, su persona, reinado y dinastía, Madrid: Castalia, 1977.

Roudinesco, E. y Michel Plon. Diccionario de Psicoanálisis. Buenos Aires : Editorial Planeta, 1998.

Stuven, Ana María. "Feminismo y femineidad: Martina Barros de Orrego a 150 años de su muerte". Mayo 2010 http: / / www.uc.cl/ historia/ cinfo/ Articulos/stuven1.html

Weininger, Otto. Sex and Character. 1903. Trad. Robert Willis. Septiembre, 2008. http: / / www.theabsolute.net/ ottow/geschlecht.pdf 